20 Meade TW, Dyer S, Browne W, Townsend J, Frank OA. Low back pain of mechanical origin: randomised comparison of chiropractic and hospital outpatient treatment. BMY 1990;300:1431-6.

21 Gilbert JR, Taylor DW, Hildebrand A, Evans C. Clinical trial of common treatments for low back pain in family practice. BMf 1985;291:791 4 .

2 Deyo RA, Walsh NE, Martin DC Schoenfeld IS, Ramamurthy S. A con RA Walled controlled trial of transcutaneous electrical nerve stimulation (TENS) a

23 Manniche C, Hesselsoe G, Bentzen L. Christensen I, Lundberg E. Clinical trial of intensive muscle training for chronic low back pain. Lance 1988;ii:1473-6.

24 Evans C, Gilbert JR, Taylor DW, Hildebrand A. A randomized controlled trial of flexion exercises, education, and bed rest for patients with acute low back pain. Phvsiotherapy Canada 1987;39:96-101.

25 Coxhead CE, Inskip H, Meade TW, North WRS, Troup JDG. Multicentre trial of physiotherapy in the management of sciatic symptoms. Lancet $1981 ;$ i: $1065-8$.

26 Waterworth RF, Hunter IA. An open study of diflunisal, conservative and manipulative therapy in the management of acute mechanical low back pain. $N Z$ Med f 1985:95:372-5.

27 Stankovic $\mathrm{R}$, Johnell $\mathrm{O}$. Conservative treatment of acute low back pain: a prospective randomized trial. Spine 1990;15:120-3.

28 Nwuga VCB. Relative therapeutic efficacy of vertebral manipulation and
1982;61:273-8.

Tarrell JP, Twomey LT Acute low back pain: compari treatment approaches. Med f A ust 1982;1:160-4.

Kendall PH, Jenkins JM. Exercises for backache: a double-blind controlled trial. Physiotherapy 1968;54:154-7.

31 Davies JR, Gibson T, Tester $\mathrm{L}$. The value of exercises in the treatment of low back pain. Rheumatology and Rehabilitation 1979;18:243-7.

32 Buswell J. Low back pain: a comparison of two treatment programmes. New Zealand fournal of Physiotherapy 1982:10:13-7.

33 Nwuga G, Nwuga V. Relative therapeutic efficacy of the Williams and McKenzie protocols in back pain management. Physiotherapy Practice 1985;1:99-105

34 White AWM. Low back pain in men receiving workmen's compensation. Can Med Assoc f 1966;95:50-6

35 Chalmers TC, Smith H, Blackburn B, et al. A method for assessing the quality of a randomized control trial. Controlled Clin Trials 1981;2:31-49.

36 Tysen J, Furzan J, Reisch J, et al. An evaluation of the quality of therapeutic trials in perinatal medicine. $\mathcal{F}$ Pediatr 1983;102:10-3.

37 Kleijnen J, Knipschild P, Ter Riet G. Clinical trials of homoeopathy. BMF 1991;302:316-23.

(Accepted 25 April 1991$)$

\title{
Complications of pregnancy and delivery in relation to psychosis in adult life: data from the British perinatal mortality survey sample
}

\author{
D John Done, Eve C Johnstone, Christopher D Frith, Jean Golding, Peter M Shepherd, \\ Timothy J Crow
}

\section{Abstract}

Objective-To evaluate whether events occurring at or around the time of birth contribute to the onset of psychotic illness in adult life.

Design-Pregnancy and birth complications as possible causes of adult mental illness were studied in the population sample of the British perinatal mortality survey. Subsequent psychiatric admissions were independently identified through the Mental Health Enquiry and records of regional and special health authorities. Logistic regression was used to compare data on perinatal deaths with those on survivors to determine factors independently associated with perinatal death, and this equation was then used to calculate the risk of perinatal death for each survivor.

Subjects -16980 people born in a single week in 1958 (the British perinatal mortality survey sample), including 252 patients admitted to psychiatric care; case notes of 235 patients were supplied.

Main outcome measures and results-Patients

Division of Psychiatry, Clinical Research Centre Watford Road, Harrow, Middlesex HA1 3UJ

D John Done, PHD, senior research officer

Eve C Johnstone, FRCPSYCH, consultant psychiatrist

Christopher D Frith, PHD, senior scientist

Timothy J Crow, FRCPSYCH, head of division

Institute of Child Health, Royal Hospital for Sick Children, Bristol BS2 8B

Jean Golding, PHD, reader in child health

Social Statistics Research Unit, City University, London EC1V OBH

Peter M Shepherd, BA, senior research fellow

Correspondence to:

Dr Done. have been assessed, of $2-3 \% .^{1-3}$ The role of genetic factors has been established by twin ${ }^{4-6}$ and adoption studies. ${ }^{78}$ It is often assumed there are also environ- $\mathcal{C}$ mental contributions, but their nature is obscure.

One suggestion is that brain damage occurring at or around the time of birth in some way contributes to the later onset of psychosis. ${ }^{9-11}$ The time interval (on 6 average over 20 years) means that there are substantial. practical difficulties in examining an association between perinatal trauma and the later development of psychosis. There have been two types of study: the first (retrospective) has identified a sample of schizophrenic patients and obtained information about their birth $\stackrel{\varnothing}{\varnothing}$ histories; the second (high risk) studied the confine- $\overrightarrow{\overrightarrow{0}}$ ments of mothers with schizophrenia, whose children are at high risk of going on to develop schizophrenia.

Retrospective studies (reviewed in table I) ${ }^{9.20}$ may include carefully selected and documented schizophrenic patients, but it is often difficult to obtain birth histories of good quality. Table I shows that in seven of 13 studies data were collected in whole or in part by asking the mother to recollect quite specific details after the patient had become ill (that is, after the passage of 20 or more years). Clearly neither she nor 0 the person recording the history would have been blind $J$ to the fact that the patient had become mentally ill, and $\mathcal{N}$ it cannot be assumed that this knowledge did not affect $\rightarrow$ the information given or recorded. A more appropriate method is to make use of birth histories recorded N before the onset of illness - that is, obtained through $\mathrm{NJ}^{\mathrm{N}}$ reference to obstetric records. Such records are often unsystematic, and they have been shown to be prone to error. ${ }^{21}$ The weakness of retrospective studies has been discussed by Lewis, who stated that the link between schizophrenia and a history of presumed obstetric 0 complications "hides a wide discrepancy in methodo- 음 logy between studies. Paradoxically, the main $\stackrel{\mathbb{D}}{\Omega}$ similarity between the studies is their collective weak- $\mathbb{\mathbb { D }}$ ness: the use of retrospective assessment of obstetric histories even if assessed blindly."

High risk studies ${ }^{23-28}$ may acquire birth histories of a high quality, but accounts of the mental states of the offspring in the period of maximum risk for schizo- $\frac{\bar{\partial}}{7}$ phrenia in adult life are usually not available.

The separate limitations of retrospective and high risk studies can be overcome only by a systematic collection of birth histories of a large cohort in which a 


\begin{tabular}{|c|c|c|c|}
\hline Study & Sample & Source & Results \\
\hline Dalen $(1965)^{1:}$ & 27 With manic psychotics; no controls & $\begin{array}{l}\text { Maternity records or reports } \\
\text { from a relative }\end{array}$ & Complications increased in familial $v$ non-familial cases $(p=0 \cdot 25)$ \\
\hline Lane and Albee $(1966)^{13}$ & 52 Schizophrenics; 115 siblings & $\begin{array}{l}\text { Birth certificate including } \\
\text { birth weight }\end{array}$ & $\begin{array}{l}\text { Schizophrenics weighed } 7 \mathrm{lbs}(3200 \mathrm{~g}) \text {, siblings } 7.5 \mathrm{lbs}(3400 \mathrm{~g}) \\
(\mathrm{p}<0.01)\end{array}$ \\
\hline Pollack et al (1966) $)^{14}$ & 33 Schizophrenics $v$ siblings & $\begin{array}{l}\text { Questionnaire completed by } \\
\text { mother }\end{array}$ & No difference between groups \\
\hline Pollack et al (1968)" & 51 Schizophrenics; no controls & Maternal reports & Early onset schizophrenics had more complications $(\mathrm{p}<0.01)$ \\
\hline Woerner et al $(1973)^{4}$ & 46 Schizophrenics $v$ siblings; 67 personality disorders $v$ siblings & $\begin{array}{l}\text { Hospital records; mothers' } \\
\text { reports }\end{array}$ & Only schizophrenics had more risk of complications $(p<0 \cdot 02)$ \\
\hline McNeil and Kaij $(1978)^{10}$ & 56 Process schizophrenics; 46 with schizophrenia-like psychoses & Hospital records & $\begin{array}{l}\text { Risk of complications increased in process schizophrenics but not } \\
\text { in those with schizophrenia-like psychoses }(p=0.04)\end{array}$ \\
\hline Jacobsen and Kinney $(1980)^{16}$ & 35 Adopted schizophrenics $v$ with normals & Midwife records & $\begin{array}{l}\text { Frequency, but not severity, of complications was raised in } \\
\text { adopted schizophrenics }(p<0 \cdot 10)\end{array}$ \\
\hline Parnas et al $(1982)^{1923}$ & $\begin{array}{l}31 \text { Non-adopted schizophrenics } v \text { normals } \\
13 \text { Schizophrenics; } 29 \text { borderline schizophrenics; } 55 \text { with no } \\
\text { mental illness }\end{array}$ & Midwife records & $\begin{array}{l}\text { Severity increased only in non-adopted schizophrenics }(p<0.05) \\
\text { Schizophrenics had more complications than borderline }(p<0.009) \\
\text { but not more than controls }(p>0.05)\end{array}$ \\
\hline Lewis and Murray (1987)" & 207 Schizophrenics; 748 other psychiatric patients & $\begin{array}{l}\text { Questionnaire completed by } \\
\text { relative }\end{array}$ & Schizophrenics had more complications $(\mathrm{p}<0.001)$ \\
\hline Owen et al (1988) & 61 Schizophrenics & $\begin{array}{l}\text { Reports in psychiatric case } \\
\text { notes and computed } \\
\text { tomography scan data }\end{array}$ & $\begin{array}{l}\text { Some structural changes on scan commoner in patients with } \\
\text { obstetric complications }\end{array}$ \\
\hline Olsen et al (1989) ${ }^{1 \times}$ & $\begin{array}{l}\text { Schizophrenics, patients with schizo-affective psychosis; bipolar } \\
\text { depressives; controls }\end{array}$ & Parental reports & No difference between groups \\
\hline Reddy et al (1989) ${ }^{19}$ & Schizophrenics and patients with bipolar affective disorder & Not stated & More complications in schizophrenics \\
\hline Eagles et al (1989) & 36 DSM-III schizophrenics; 36 sibling controls & Maternity records & $\begin{array}{l}\text { Frequency }(p<0.002) \text { and severity }(p<0.025) \text { of complications } \\
\text { greater in schizophrenics }\end{array}$ \\
\hline
\end{tabular}

proportion develops psychosis in adulthood. The study reported here used the well documented birth histories from the British perinatal mortality survey ${ }^{28}$ and screened all psychiatric admissions to hospitals in England, Scotland, and Wales during 1974-86 for patients who were a part of this birth cohort.

\section{Method}

SOURCES OF DATA

The study population comprised about 16980 births registered during the week 3-9 March 1958, representing $98 \%$ of all births in England, Scotland, and Wales in that week (the British perinatal mortality survey $\left.{ }^{28}\right)$. At that time the stillbirth and neonatal mortality rate was 35 per 1000 births; the main purpose of the perinatal mortality survey was to examine social and obstetric factors associated with such deaths. In 1974 the Mental Health Enquiry was set up, and it recorded data on all psychiatric admissions between 1974 and 1986. From this source the records of every patient with a date of birth between 3 March and 9 March 1958 (and thus every member of the study cohort) who had been admitted to psychiatric care between 1974 and 1986 could be identified.

\section{DATA COLLECTION}

Approval was sought for the disclosure of Mental Health Enquiry or other records for all admissions born 3 to 9 March 1958 from each of the 15 regional health authorities, two special health authorities, and four special hospitals. With permission granted, the regional statistician screened the tapes of the Mental Health Enquiry and identified the patients. Consent was sought from consultants in charge to send the notes to the investigators. In all, 698 admissions were notified, but these included many readmissions and in total represented 252 patients. In four cases the consultant refused permission for inclusion in the study, and in 13 cases the notes were irretrievably lost. This meant that 235 sets of case notes were sent to Northwick Park. The syndrome checklist of the present state examination ${ }^{29}$ was applied (by ECJ), and a survey form recording histories of previous admissions, medication, education, and employment as well as family history, social decline, and police contact was completed (by DJD). Table II shows the nature of the sample finally obtained in terms of schizophrenia and affective psychosis classifications derived from the present state examination (PSE) by application of the CATEGO program.

In fact the numbers reported here are surprisingly representative of a disease with a lifetime prevalence of $0.8 \%$ to $1 \%$. Estimates for proportion of lifetime risk used up by age 27 (derived from data from England and Wales $1952-60^{30}$ ) are 0.40 for men and 0.32 for women, giving an average of $0 \cdot 36$. Data provided by the Social Statistics Unit for the national child development study shows that by age 23 the expected number in the cohort was 16457 (if immigrants are included and emigrants and deaths excluded). Extrapolating this would reduce the cohort to approximately 16000 by age 27. Therefore (assuming a lifetime prevalence of either $0.8 \%$ or $1 \%$ ) the expected number of schizophrenic individuals is $(0.008$ to 0.01$) \times 0.36 \times 16000=$ $46 \cdot 1$ to $57 \cdot 6$. These values compare with the obtained values in table II of 49 for the "narrow" diagnosis of schizophrenia and 79 for the broad category of schizophrenia using PSE-CATEGO diagnosis. It should be noted that the figures of 0.45 for men and 0.27 for women for proportion of risk used by age 30 from data for England and Wales between 1970 and 1981 reported by Der et $a l^{31}$ would give closely similar expectations.

\section{METHOD OF ANALYSIS}

We assumed (as did retrospective studies) that the nature of the prenatal and perinatal events relevant to the later development of schizophrenia was the same as those responsible for stillbirth and neonatal death. Logistic regression analysis was used to derive the probability of stillbirth or neonatal death for each

TABLE II-Cases recorded by Mental Health Enquiry with dates of birth 3-9 March 1958

\begin{tabular}{|c|c|c|c|c|c|c|c|c|}
\hline & \multicolumn{3}{|c|}{ Broad category of schizophrenia } & \multicolumn{3}{|c|}{ Affective psychosis } & \multirow[b]{2}{*}{ Neurosis } & \multirow[b]{2}{*}{$\begin{array}{c}\text { No } \\
\text { abnormality }\end{array}$} \\
\hline & $\begin{array}{c}\text { Narrow } \\
\text { schizophrenia }\end{array}$ & $\begin{array}{l}\text { Paranoid } \\
\text { psychosis }\end{array}$ & $\begin{array}{c}\text { Other } \\
\text { psychosis }\end{array}$ & Mania & $\begin{array}{l}\text { Depressive } \\
\text { psychosis }\end{array}$ & $\begin{array}{c}\text { Retarded } \\
\text { depression }\end{array}$ & & \\
\hline CATEGO diagnosis $^{32}$ & $\mathrm{~S}+/ \mathrm{S} ?$ & $\mathrm{P}+/ \mathrm{P}$ ? & $\mathrm{O}+/ \mathrm{O} ?$ & $\mathrm{M}+/ \mathbf{M} ?$ & $\mathrm{D}+/ \mathrm{D}$ ? & $\mathrm{R}+\mathrm{R}$ ? & $\mathrm{N}+/ \mathrm{N} ? / \mathrm{X}$ & NO \\
\hline Total & 49 & 10 & 20 & 15 & 9 & 20 & 93 & 20 \\
\hline No born abroad & 8 & 3 & 4 & 3 & 2 & 3 & 3 & \\
\hline Otherwise unusable & 6 & 0 & $i$ & 2 & 0 & 2 & 14 & \\
\hline No included & 35 & 7 & 15 & 10 & 7 & 15 & 76 & \\
\hline
\end{tabular}




\begin{tabular}{|c|c|c|c|}
\hline & $\begin{array}{l}\text { Average } \\
\text { probability of } \\
\text { stillbirth or } \\
\text { neonatal death }\end{array}$ & $\begin{array}{l}\text { Difference between means }{ }^{\star} \\
(95 \% \text { confidence interval })\end{array}$ & p Value \\
\hline Controls $(n=12946)$ & $0 \cdot 0098$ & & \\
\hline \multicolumn{4}{|l|}{ Diagnostic category based on PSE-CATEGO:t } \\
\hline Narrow schizophrenia $(\mathbf{n}=35)$ & $0 \cdot 0111$ & $0.0012(-0.00142$ to 0.005$)$ & $0 \cdot 40$ \\
\hline Broad schizophrenia $(\mathrm{n}=57)$ & 0.0112 & $0.0014(-0.0008$ to 0.004$)$ & 0.24 \\
\hline Affective psychosis $(n=32)$ & 0.0125 & $0.0027(-0.0005$ to 0.007$)$ & $0 \cdot 105$ \\
\hline Neurosis $(\mathbf{n}=75)$ & 0.0103 & $0.0005(-0.001$ to 0.0027$)$ & 0.60 \\
\hline \multicolumn{4}{|l|}{ Diagnosis from case notes: } \\
\hline Schizophrenia $(n=37)$ & 0.0121 & $0.0022(-0.0006$ to 0.006$)$ & $0 \cdot 14$ \\
\hline Affective psychosis $(n=31)$ & 0.0106 & $0.0008(-0.0007$ to 0.0026$)$ & 0.60 \\
\hline
\end{tabular}

Estimated average probability (p) was derived from the dependent variable (log odds) according to the formula $\log$ odds $=\ln \frac{p}{1-p}$.

$\star \overline{\mathrm{X}}_{\text {Patient }}-\overline{\mathrm{X}}_{\text {Control }}$.

†Present state examination.

cohort member. This will be referred to as "the risk." The method of logistic regression establishes those variables that uniquely explain some of the risk and appropriate weights for these variables.

All subjects from the perinatal mortality survey were recorded as being either alive or dead after the first week of life. Given these data the logistic regression program was used to formulate the optimal equation for predicting whether a subject is dead or alive. The equation is given in the appendix. Certain variables were rejected, either because they are variables of insignificant risk or because their contribution to risk has been covered by others already included in the equation. The advantages of this method over summing the occurrence of selected high risk variables are that only those variables that increased the risk within the cohort itself were used; high risk variables that covary with other risk variables could be excluded (see table A2 of the appendix); and those variables that carry a greater degree of risk were given due weighting.

The equation that results can then be used to calculate the risk to each cohort member. In this way an average risk can be obtained for a particular group within the cohort (for example, schizophrenics), which can then be compared with the control group (that is, the well members of the cohort) with a $t$ test.

\section{Results}

Table III shows that the risk is not significantly greater for any of the diagnostic groups. This form of analysis treats all cases within the patient group equally. In this way an extreme subgroup may be

TABLE IV-Odds ratio of stillbirth or neonatal death in different diagnostic groups

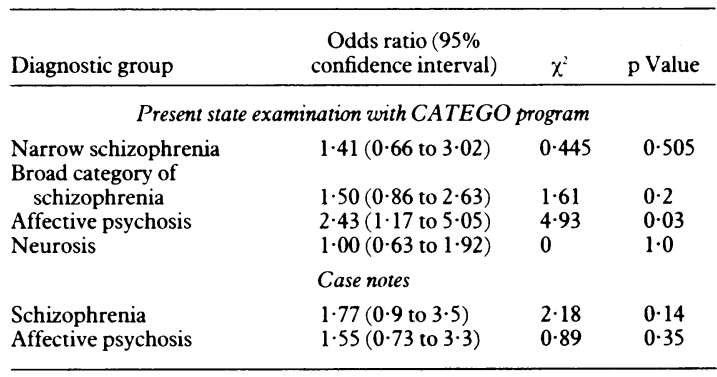

TABLE V-Family histories of psychiatric illness in relatives of patients with narrowly defined schizophrenia and affective psychosis (diagnosis according to present state examination categories)

\begin{tabular}{|c|c|c|c|c|}
\hline \multirow[b]{2}{*}{ Information from case notes } & \multicolumn{2}{|c|}{ Narrowly defined schizophrenia $(n=49)$} & \multicolumn{2}{|c|}{ Affective psychosis $(n=44)$} \\
\hline & $\begin{array}{l}\text { No of patients } \\
\text { with first degree } \\
\text { relatives } \\
\text { affected }\end{array}$ & $\begin{array}{c}\text { No of patients } \\
\text { with any relatives } \\
\text { affected }\end{array}$ & $\begin{array}{l}\text { No of patients } \\
\text { with first degree } \\
\text { relatives affected }\end{array}$ & $\begin{array}{c}\text { No of patients } \\
\text { with any } \\
\text { relatives } \\
\text { affected }\end{array}$ \\
\hline No family history available & 16 & 13 & 24 & 20 \\
\hline Inadequate information given & 10 & 10 & 9 & 9 \\
\hline Unspecified mental illness & 14 & 14 & 5 & 8 \\
\hline Affective illness & 3 & 3 & 6 & 7 \\
\hline Schizophrenia & 5 & 6 & & \\
\hline Mental handicap & 1 & 3 & & \\
\hline
\end{tabular}

missed; the small increase in relative risk in psychiatric groups previously reported might result from the presence of a subgroup with an exceptionally high risk. To assess this possibility the $30 \%$ of patients at the greatest risk in each patient group were selected and the risk value (the probability of stillbirth or neonatal death) that distinguished this subgroup from the rest of their group was used as a cut off point. This value could then be used to find the proportion of the well control group that was at similarly high risk. From this a $2 \times 2$ table could be made of high $v$ low risk against patient $v$ control and a $\chi^{2}$ test used to test for an increased risk in the patient group (odds ratio). Table IV presents the data for this analysis.

The results in table IV indicate that there is no significant increase in risk for schizophrenic patients, regardless of the diagnostic scheme adopted. It may be argued that because the odds ratio for the schizophrenic group is consistently above unity (although the groups are of course overlapping) a larger sample size might have revealed a significant effect. Even if this were the case, the association might still be a consequence of something about the mother (for example, she has a diagnosis of schizophrenia) rather than obstetric complications.

In the PSE-CATEGO affective psychotic group the odds ratio was $2.43(p=0.03)$. This increased risk remained significant $(p=0.04)$ with a cut off set at $40 \%$ but was less clear $(p=0 \cdot 10)$ if the cut off point was set at $25 \%$.

The analysis of the data so far utilised an equation that optimally predicts stillbirth or neonatal death. However, the relation between the high risk variables and adult psychosis might well be different. For example, an equation that would predict intracranial haemorrhage or some other cerebral insult might be preferable. No such model at present is available, but in the absence of a model an exploratory analysis was conducted in an attempt to devise an equation that would predict each of the diagnoses from the list of variables significantly and independently associated with stillbirth or infant mortality. The list includes maternal variables - parity, all bleeding in pregnancy or before delivery, maternal weight before pregnancy, duration of gestation, toxaemia, duration of second stage of labour, time between rupture of membranes and delivery, induction of labour, method of delivery, inhalation analgesia, influenza, gastrointestinal disorder, hydramnios, and falls and accidents; and infant variables - birth weight and administration of Coramine (nikethamide), sedatives, antagonists, Synkavit (menadiol sodium diphosphate), penicillin, or other drugs.

Each individual in the cohort was designated as either a well control or a patient in terms of the PSE-CATEGO classification (table II). Using logistic regression, the variables significantly associated with membership of each diagnosis group separately were determined. "Narrow" schizophrenia was significantly associated with maternal weight $(8.6$ stones $(54.6 \mathrm{~kg})$ (SD 2.86 stones $(18.2 \mathrm{~kg})$ ) $v 9.0$ stones $(57.2 \mathrm{~kg}$ ) (SD 2.94 stones $(18.7 \mathrm{~kg})$ ) in cohort; $\chi^{2}=7 \cdot 7, \mathrm{df}=4$, $\mathrm{p}=0 \cdot 10$ ) and "other" drugs (non-routine drugs were given to two patients in the first week of life: $\chi^{2}=3 \cdot 3$, $\mathrm{df}=1, \mathrm{p}=0.07$ in comparison with cohort). The broad category of schizophrenia was significantly associated with maternal weight $(8.6$ stones $(54.6 \mathrm{~kg}) v 9.0$ stones $(57 \cdot 2 \mathrm{~kg})$ in cohort, $\left.\chi^{2}=13 \cdot 5, \mathrm{df}=4, \mathrm{p}=0.01\right)$. Affective psychosis was significantly associated with length of gestation (mean 273.9 $(17 \cdot 8)$ days $v 281 \cdot 2(12 \cdot 1)$ days in cohort, $\left.\chi^{2}=9 \cdot 2, \mathrm{df}=1, \mathrm{p}<0.002\right)$ and prescription of Synkavit, a fat soluble form of vitamin $\mathrm{K}$ which was given to the baby when there was a risk of haemorrhage at the time of birth; it was given to six $(19 \%)$ patients with affective psychosis and $816(5 \%)$ controls $\left(\chi^{2}=5 \cdot 8\right.$, 
$\mathrm{df}=1, \mathrm{p}=0 \cdot 016)$. Bleeding during the pregnancy was commoner in subjects with neurotic disorder than in controls $\left(\chi^{2}=4 \cdot 9, \mathrm{df}=2, \mathrm{p}=0 \cdot 09\right)$.

\section{Discussion}

The findings presented here offer little support for the suggestion that some schizophrenic illnesses are a result of birth trauma or a high risk pregnancy. When either a narrow or a broad diagnosis based on the present state examination is adopted there is no significant difference between schizophrenic patients and normal controls in risk of early death from exposure to high risk variables. There was also no support for the notion that there was a small group of schizophrenic patients who had an exceptionally risky gestation or birth. However, an increased prevalence of cases with a high risk was found (in the subgroup analysis) in the group of patients with affective psychoses. The large group of neurotic subjects did not differ from the control groups.

The strength of these findings should be considered in the light of what is known about these data sets. Reliability can be assessed from the quality of the perinatal mortality survey and of the psychiatric diagnoses obtained from histories in the case notes. The high quality of the survey data is well supported by other studies with replicated findings that have used this source of data over the last 20 or so years. ${ }^{32}{ }^{33}$ The quality of the PSE-CATEGO diagnosis is less certain because it depends on case notes of variable styles. Examination of family histories obtained from case notes before the syndrome checklist was applied offers some support for the classification. Table V shows family histories of the patients narrowly defined as schizophrenic and of those with affective illness $(n=44)$. Of the schizophrenic patients, five of 39 $(12 \cdot 8 \%)$ for whom adequate information was available had a first degree relative with schizophrenia and three $(7 \cdot 7 \%)$ a first degree relative with affective illness. The patients with affective psychosis had no relatives with schizophrenia but six out of 35 with documentation

TABLE A1 - Independent variables included in the model and their weights

\begin{tabular}{|c|c|c|c|c|c|}
\hline Variable & $\begin{array}{l}\text { Reference } \\
\text { category }\end{array}$ & $\begin{array}{l}\text { Contrast } \\
\text { categories }\end{array}$ & Coefficient & SE & $\begin{array}{l}\text { Coefficient } \\
\text { SE }\end{array}$ \\
\hline Constant & & & $34 \cdot 24$ & $2 \cdot 427$ & $14 \cdot 11$ \\
\hline Parity & First & $\begin{array}{l}\text { Second } \\
\text { Third } \\
\geqslant \text { Fourth }\end{array}$ & $\begin{array}{r}-0.225 \\
-0.013 \\
0.050\end{array}$ & $\begin{array}{l}0.123 \\
0 \cdot 125 \\
0 \cdot 174\end{array}$ & $\begin{array}{r}-1 \cdot 83 \\
-0 \cdot 10 \\
0.29\end{array}$ \\
\hline All bleeding & None & $\begin{array}{l}>28 \\
<28\end{array}$ & $\begin{array}{r}0.912 \\
-0.606\end{array}$ & $\begin{array}{l}0.207 \\
0 \cdot 292\end{array}$ & $\begin{array}{l}4 \cdot 416 \\
-2 \cdot 07\end{array}$ \\
\hline Birth weight (grams) & $<2500$ & $\begin{aligned} & 2501-3000 \\
& 3001-4000 \\
\geqslant & 4001\end{aligned}$ & $\begin{array}{r}-0.291 \\
-0.147 \\
0.158\end{array}$ & $\begin{array}{l}0 \cdot 15 \\
0 \cdot 108 \\
0 \cdot 151\end{array}$ & $\begin{array}{r}-1.94 \\
-1.37 \\
1.05\end{array}$ \\
\hline Maternal weight (stones) & $<8$ & $\begin{aligned} & 8 \text { to }<9 \\
& 9 \text { to }<10 \\
& 10 \text { to }<11 \\
& \geqslant 11\end{aligned}$ & $\begin{array}{r}-0 \cdot 255 \\
-0 \cdot 120 \\
-0.087 \\
0.296\end{array}$ & $\begin{array}{l}0 \cdot 122 \\
0 \cdot 121 \\
0 \cdot 148 \\
0 \cdot 142\end{array}$ & $\begin{array}{l}-2 \cdot 1 \\
-0.998 \\
-0.589 \\
2.08\end{array}$ \\
\hline Gestation (months) & Continuous & & $-0 \cdot 135$ & 0.009 & $-14 \cdot 16$ \\
\hline Toxaemia & Normal & Abnormal & 0.402 & 0.091 & $4 \cdot 43$ \\
\hline $\begin{array}{l}\text { Duration of second stage } \\
\text { of labour (minutes) }\end{array}$ & None & $\begin{array}{c}<60 \\
\quad 60-120 \\
>120\end{array}$ & $\begin{array}{l}0 \cdot 892 \\
0 \cdot 177 \\
0 \cdot 058\end{array}$ & $\begin{array}{l}0.169 \\
0.203 \\
0.238\end{array}$ & $\begin{array}{l}5 \cdot 29 \\
0 \cdot 873 \\
0 \cdot 244\end{array}$ \\
\hline $\begin{array}{l}\text { Duration membranes } \\
\text { ruptured (hours) }\end{array}$ & None & $\begin{array}{l}<24 \\
>24\end{array}$ & $\begin{array}{r}-0 \cdot 201 \\
0 \cdot 182\end{array}$ & $\begin{array}{l}0 \cdot 199 \\
0 \cdot 204\end{array}$ & $\begin{array}{r}-1 \cdot 01 \\
0.89\end{array}$ \\
\hline $\begin{array}{l}\text { Labour induced } \\
\text { Method of delivery } \\
\text { Inhalation analgesia } \\
\text { Influenza during }\end{array}$ & $\begin{array}{l}\text { No } \\
\text { Normal } \\
\text { Yes }\end{array}$ & $\begin{array}{l}\text { Yes } \\
\text { Complex } \\
\text { No }\end{array}$ & $\begin{array}{l}0 \cdot 164 \\
0 \cdot 731 \\
0 \cdot 25\end{array}$ & $\begin{array}{l}0.084 \\
0.089 \\
0.076\end{array}$ & $\begin{array}{l}1.96 \\
8 \cdot 24 \\
3 \cdot 29\end{array}$ \\
\hline pregnancy & No & Yes & $0 \cdot 25$ & 0.084 & $2 \cdot 94$ \\
\hline $\begin{array}{l}\text { Gastrointestinal disorders } \\
\text { during pregnancy } \\
\text { Hydramnios } \\
\text { Falls and accidents }\end{array}$ & $\begin{array}{l}\text { No } \\
\text { No } \\
\text { No }\end{array}$ & $\begin{array}{l}\text { Yes } \\
\text { Yes } \\
\text { Yes }\end{array}$ & $\begin{array}{l}0 \cdot 71 \\
1 \cdot 29 \\
0.653\end{array}$ & $\begin{array}{l}0.175 \\
0 \cdot 17 \\
0.30\end{array}$ & $\begin{array}{l}4 \cdot 07 \\
7 \cdot 56 \\
2 \cdot 175\end{array}$ \\
\hline \multicolumn{6}{|l|}{ Prescription of drugs to baby: } \\
\hline $\begin{array}{l}\text { Coramine } \\
\text { Sedatives } \\
\text { Antagonists } \\
\text { Synkavit } \\
\text { Penicillin } \\
\text { Other drugs }\end{array}$ & $\begin{array}{l}\text { No } \\
\text { No } \\
\text { No } \\
\text { No } \\
\text { No } \\
\text { No }\end{array}$ & $\begin{array}{l}\text { Yes } \\
\text { Yes } \\
\text { Yes } \\
\text { Yes } \\
\text { Yes } \\
\text { Yes }\end{array}$ & $\begin{array}{r}0.83 \\
0.447 \\
-1.306 \\
-0.241 \\
0.723 \\
0.517\end{array}$ & $\begin{array}{l}0 \cdot 17 \\
0 \cdot 22 \\
0 \cdot 65 \\
0 \cdot 122 \\
0 \cdot 142 \\
0 \cdot 154\end{array}$ & $\begin{array}{r}4 \cdot 99 \\
2 \cdot 03 \\
-2 \cdot 02 \\
-1 \cdot 97 \\
5 \cdot 1 \\
3 \cdot 35\end{array}$ \\
\hline
\end{tabular}

$(17 \cdot 1 \%)$ had first degree relatives with affective illness.

The exploratory analysis isolated specific risk variables associated with each diagnostic category. Two variables were associated with narrowly defined schizophrenia. These were maternal weight (mothers of schizophrenic patients tended to weigh less than mothers of normal subjects) and "other drugs" given to the baby. The drugs concerned were antibiotics given to two babies (who were in fact the children of schizophrenic mothers) for skin sepsis and septic ear. The maternal weight effect does not seem to be a spurious association; the significance holds up for a narrow $(p=0.052)$ and a broad definition $(p=0.01)$ of schizophrenia. In the group of neurotic patients the only variable that approached significance was bleeding during pregnancy.

The only group in which a significant relation in the main analysis was found was that of affective psychosis. $\vec{\circ}$ The variables of most significance were duration of gestation (shorter by some $7 \cdot 3$ days in subjects with $\vec{\omega}$ affective disorder) and prescription of Synkavit to the baby. The reasons for giving Synkavit were forceps delivery, premature delivery, moulding of the head, and routine (one case each), and there was no reason $\stackrel{\sim}{N}$ given in two cases. None of these babies were recorded as preterm $(<259$ days' gestation $)$.

\section{Conclusions}

The intention of this study was to take advantage of the perinatal mortality survey sample so that technical difficulties could be overcome. These difficulties had $\subseteq$ led Mednick to state that a prospective birth cohort study of perhaps 10000 consecutive deliveries in a well $\vec{\theta}$ defined area and time was clearly the only satisfactory $\bullet$ approach to comparing high risk and low risk. ${ }^{34}$. Although our sample exceeded these requirements, our result is not as definitive as we had hoped. On their own the findings in the schizophrenic patients can be taken as providing evidence against a role for early brain injury as an aetiological factor in schizophrenia. The findings on affective patients raise a number of $\overrightarrow{\overrightarrow{0}}$ questions. We cannot know what a standardised interview (rather than case note review) might have revealed or what diagnostic picture these cases of affective illness of early onset may finally show. Perhaps affective illness is truly associated with reduced mean gestation time or other perinatal anomaly; possibly some of the affective patients will $\exists$ turn out to have schizophrenia later. The results do, however, show that if there is an effect of perinatal trauma on the later development of psychotic illness it is weak, difficult to define, and apparently absent in typical schizophrenia of early onset.

We thank all the medical officers, consultant psychiatrists, general practitioners, and regional statistical staff and all N other NHS and national child development study staff who N put in considerable time and effort on behalf of this study. Thanks are also due to Gareth Roberts, Bob Woody, Jo Pearson, and Caroline Doré for their advice.

\section{Appendix}

In the logistic regression model of the form:

$$
y=\delta+\beta_{1} X_{1}+\beta_{2} X_{2} \ldots
$$

$\mathrm{y}$ is the log odds of stillbirth and neonatal mortality; $\delta$ is the constant; $\beta_{1 \ldots n}$ the coefficients of the independent variables $X_{1 \ldots n} \cdot X_{1}$ and $X_{2}$ are unrelated and hence separate variables $O$ such as the interval variable "gestation" (days) or the categorical variable "toxaemia" (present or absent); or $\mathrm{X}_{1}$ and $\mathrm{X}_{2}$ 흘 can be "design variables" for a categorical variable with three categories. For such categorical variables with $\mathrm{k}$ categories, $\mathrm{k}-1$ design variables are generated by using the BMDP logistic regression program.

Table Al gives a complete list of the independent variables 
TABLE A2 - Independen variables significantly associated with still-birth or neonatal death excluded from model because of covariance

Height of mother

Number of previous premature births

Haemoglobin concentration

Duration of first stage of labour

Maternal age

Fetal distress (cord/prolapse/

meconium/fetal heart)

meconium/tetal heart)
Social and economic status

Social and economic status
Fever/tonsillitis/laryngitis

Fever/tonsillitis/laryngitis
Urinary tract infection

Urinary tract infection

Type of resuscitation
Prescription of drugs to baby

Prescription

Streptomycin included in the model that optimally estimates the log odds of stillbirth or neonatal death in the whole British perinatal mortality survey (1958) cohort. This list of variables includes the names of categorical variables together with the design variables that are generated (for example, "parity" is a categorical variable with four categories and hence three design variables labelled as " 1 ", “2", “3”), as well as their coefficients. Categorical variables with two categories have been listed in table A2 as having only a single entry in the model. No interactions were included in the model owing to the computational problems that these would have generated for little improvement of the model.

1 Hare EH. Epidemiology of schizophrenia and affective psychoses. Br.Med Bull 1987:43:514-30

2 Eaton WW. Epidemiology of schizophrenia. Epidemiol Rev 1985;7:105-26.

3 Weissman MM, Bovd JH. The epidemiology of affective disorders. In: Post RM, Ballenger JC, eds. Neurobiology of mood disorders. Baltimore: W'illiams and Wilkins, 1984:60-75.

4 Gottesman II, Shields J. Schizophrenia and genetics: a twin vantage point New York: Academic, 1972

5 Kendler KS, Robinette CD. Schizophrenia in the NAS-NRC twin registry: a 16 year update. Am F Psychiatry 1983;140:1551-63.

6 Bertelsen A, Harvald B, Hauge M. A Danish twin study of manic-depressive disorders. Br f Psychiatry 1977;130:330-51.

7 Kety SS. Mental illness in the biological and adoptive relatives of schizophrenic adoptees: findings relevant to genetic and environmental factors in etiology. Am J Psychiatry 1983;140:720-7.

8 Mendelwicz J, Rainer JD. Adoption study supporting genetic transmission in manic-depressive illness. Nature 1977;268:327-9.

9 Woerner MG, Pollack M, Klein DF. Pregnancy and birth complications in psychiatric patients: a comparison of schizophrenic and personality disorder psychiatric patients: a comparison of schizophrenic and personality

$10 \mathrm{McNeil} \mathrm{TF}$, Kaij L. Obstetric factors in the development of schizophrenia complications in the births of preschizophrenics and in reproduction by schizophrenic patients. In: Wynne LC, Cromwell RL, Matthysse S, eds. The nature of schizophrenia. New York: Wiley, 1978:401-29.

11 Lewis SW, Murray RM. Obstetric complications, neurodevelopmental deviance and risk of schizophrenia. $\mathcal{F}$ Psychiat Research 1987;21:413-22.

2 Dalen P. Family history, the electroencephalogram, and perinatal factors in manic conditions. Acta Psychiatr Scand 1965;41:527-63.

13 Lane EA, Albee GW. Comparative birth weights of schizophrenics and their siblings. F Psychology 1966;64:227-31.

14 Pollack M, Woerner M, Goodman W, Greenberg I. Childhood development patterns of hospitalised adult schizophrenic and non-schizophrenic patients and their siblings. Am F Orthopsychiatry 1966;36:510-97.

15 Pollack M, Levenstein S, Klein DF A three year post-hospital follow-up of adolescent and adult schizophrenics. Am f Orthopsychiatry 1968;38:94-109.
16 Jacobsen B, Kinney DK. Perinatal complications in adopted and non-adopted schizophrenics and their controls: preliminary results. Acta Psychiatr Scand 1980;62(suppl 285):337-46.

17 Owen MJ, Lewis SW, Murray RM. Obstetric complications and schizophrenia: a computer tomographic study. Psychol Med 1988;18:331-9.

18 Olson SC, Nasrallah HA, Coffman JA, Schwarzkopf SB. Perinatal complications and premorbid function in psychosis. Biol Psychiatry 1989;25: 93-106A.

19 Reddy R, Mukheriee S, Schnur D. Pregnancy and birth complications and premorbid functioning in schizophrenic and bipolar patients. Bio Psychiatry 1989;25:93A.

20 Eagles JM, Gibson I, Bremner MH, Clunie F, Ebmeier KP, Smith NC. Obstetric complications in DSM-III schizophrenics and their siblings. Lancet 1990;336:1139-41.

21 Joffe M, Grisso JA. Comparison of antenatal hospital records with retrospective interviewing. I Biol Science 1985;17:113-9.

22 Lewis SW. Congenital risk factors for schizophrenia. Psychol Med 1989;19. 5-13.

23 Parnas J, Schulsinger F, Teasdale TW, Schulsinger H, Feldman PM, Mednick SA. Perinatal complications and clinical outcome within the schizophrenia spectrum. Brf Psychiatry 1982;140:416-20.

24 Wrede G, Mednick SA, Huttunen MO, Nilsson CG. Pregnancy and delivery complications in the births of an unselected series of Finnish children with schizophrenic mothers. Acta Psychiatr Scand 1980;62:369-81.

25 Mednick SA, Mura E, Schulsinger F, Mednick B. Perinatal conditions and infant development in children with schizophrenic parents. Soc Biol 1971; 18:103-13.

26 Mirdal GKM, Mednick SA, Schulsinger F, Fuchs F. Perinatal complication in the children of schizophrenic mothers. Acta Psychiatr Scand 1974;50 553-68

$27 \mathrm{McNeil}$ TF, Kaij L. Obstetric complications and physical size of offspring of schizophrenic, schizophrenic-like, and control mothers. Br $\mathcal{F}$ Psychiatry 1973;123:341-8.

28 Shepherd PM. The national child development study. An introduction to the background to the study and methods of data collection. London: Social Statistics Research Unit, City University, 1985. (Working paper No 1.)

29 Wing JK, Cooper JE, Sartorius N. The measurement and classification of psychiatric symptoms: an instruction manual for the PSE and CATEGO psychiatric symptoms: an instruction manual for the

30 Gottesman II, Shields J. Schizophrenia: the epigenetic puzzle. Cambridge University Press, 1982.

31 Der G, Gupta S, Murray RM. Is schizophrenia disappearing? Lance 1990;335:513-6.

32 Butler N, Alberman ED. Perinatal problems. Edinburgh: Livingston, 1969

33 Butler N, Goldstein H, Ross EM. Cigarette smoking in pregnancy: influence on birth and perinatal mortality. $B M \mathcal{F} 1971 ; \mathrm{i}: 127-30$.

34 Mednick SA. Berkson's fallacy and high risk research. In: Wynne LC Cromwell RC, Matthysse S, eds. The nature of schizophrenia. New York: Wiley, 1978:442-52.

(Accepted 18 April 1991)

\section{Infant feeding practices and ulcerative colitis in childhood}

\author{
S|Koletzko, A Griffiths, MYCorey, GSmith, \\ PSherman
}

\section{Division of \\ Gastroenterology, \\ Departments of Paediatrics \\ and Nursing, Research \\ Institute, Hospital for Sick \\ Children, University of \\ Toronto, Toronto, Canada \\ M5G 1X8}

S Koletzko, MD, research

fellow

A Griffiths, MD, assistant

professor

M Corey, MSC, statistician

C Smith, RN, gastroenterology

nurse

P Sherman, $\mathrm{MD}$, associate

professor

Correspondence to:

Dr Sherman.

BMf 1991;302:1580-1
Accumulating evidence indicates that events early in life, including infant feeding practices, can have long term effects on health and disease. ${ }^{1}$ We recently showed that the absence of breast feeding and early diarrhoea are independent risk factors associated with development of Crohn's disease later in childhood. ${ }^{2}$ To determine if similar risk factors were linked to the development of ulcerative colitis we carried out an epidemiological case-control study.

\section{Patients, methods, and results}

A questionnaire was sent to 118 families with at least one child with ulcerative colitis diagnosed by endoscopic and histological criteria. Data obtained included age, sex, premature delivery, diarrhoeal illnesses during the first six months of life, type of feeding used from birth, duration of exclusive breast feeding, total duration of breast feeding, and the age at which solids were introduced. As in our previous study breast feeding referred to any provision of human milk and exclusive breast feeding indicated the absence of formula milk and solids. ${ }^{2}$ Unaffected siblings served as controls to reduce the variation of genetic factors and confounding variables. Potential risk factors were analysed within families by using the conditional logistic regression model. ${ }^{2}$
Of the 118 families, $108(92 \%)$ completed the questionnaires. This included 17 children without unaffected siblings, leaving 93 affected children and 138 siblings available for analysis. The mean $(14 \cdot 2$ (SD $4 \cdot 1)$ years) and median ( 15.0 years) ages for children with ulcerative colitis were comparable with those of the group of unaffected siblings $(15 \cdot 7$ $(6 \cdot 5) ; 15 \cdot 8)$.

Multivariate analysis showed that children with ulcerative colitis were more likely to have had diarrhoeal diseases during infancy (relative risk 3.2 $(95 \%$ confidence limits $1 \cdot 15$ to $8 \cdot 75$ ), $p=0.03$ ) compared with their unaffected siblings. Female sex was also an independent risk factor $(2.3(1.23$ to 4.35$), p=0.01)$. In contrast to our previous findings for childhood Crohn's disease, ${ }^{2}$ absence of breast feeding was not significantly different among children with ulcerative colitis $(1.7$ $(0.77$ to 3.65$), p=0 \cdot 19)$. Duration of exclusive breast feeding, total length of breast feeding, and age at introduction of solid foods did not differ between children with ulcerative colitis and their siblings. Birth order and the incidence of premature delivery were comparable in the two groups.

\section{Comment}

In this study the lack of breast feeding and presence of formula feeding were not identified as risk factors for the development of childhood ulcerative colitis. This finding agrees with the results of one study $^{3}$ but contrasts with two studies in adults with ulcerative colitis $^{45}$ and our previous observation of paediatric Crohn's disease. ${ }^{2}$ Our study design reduces the possibility of recall bias because parents completed the questionnaires for both cases and controls. In addition, 